Kathryn La Barre. 2011. Returning the (faceted) gaze: Reflections on representation, meaning and form. In Smiraglia, Richard P., ed. Proceedings from North American Symposium on Knowledge Organization, Vol. 3. Toronto, Canada, pp. 130-138.

Kathryn La Barre(klabarre@illinois.edu)

University of Illinois at Urbana-Champaign, Champaign, IL USA,

\title{
Returning the (Faceted) Gaze: Reflections on Representation, Meaning and Form
}

\begin{abstract}
This brief position paper is the central narrative in a theoretic-historical triptych. The first two documents: A (Faceted) Semantic Web? (La Barre, 2011) and Traditions of Facet Theory or a Garden of Forking Paths? (La Barre, forthcoming) amplify a question Brian Vickery posed to the author in 2005. The current proposal, deeply entwined in the same narrative, seeks to continue the agenda of articulation for a primarily North American audience. Instead of description and comparison, a starkly different analytical framework - Walter Benjamin's notion of 'aura' - is deployed to interrogate facet theory along the core dimensions of tradition, uniqueness, and authenticity. The final aspect of this proposal will be an investigation of the aesthetic of redemption that may well serve as the bedrock for operational definitions and functional requirements for facet theory.
\end{abstract}

\subsection{Introduction}

This position paper forms the central narrative in a theoretic-historical triptych. The first two documents: A (Faceted) Semantic Web? (La Barre, 2011) and Traditions of Facet Theory or a Garden of Forking Paths? (La Barre, forthcoming) amplify a question Brian Vickery posed to the author in 2005,

Do we in fact need a much richer representation of semantic relationships [than provided by facets], such as some ontologies are now trying to achieve? (Personal correspondence).

The narrative of the latter work (La Barre, 2011) interrogated the early onset of terminological vagaries in the language of facet theory (de Grolier, 1962, p. 15). By examining facet theory through the lens of tradition, it found a far more nuanced reality than is commonly offered by explanations that assert national or disciplinary boundaries as chief agents in differing theoretical and practical instantiations. This antecedent history is now indelibly manifest in contemporary understandings of 'facet' that are increasingly unstable and conflicting. The former work (La Barre, forthcoming) appraised the future of facet theory on the Semantic Web within the context of artifacts in diverse digital environments - ranging from library catalogs to Semantic technologies (Maniez, 1999; La Barre, 2010).

Each paper targeted different audiences, the first primarily Francophile, and the second largely British, but both concluded with the entreaties of Murray (2003) and Slavic (2008) for articulation work that involves explication of operational definitions and functional requirements for facet theory. The author agrees with these and other researchers who maintain that facet theory will fail to realize full potential in digital environments without such an agenda. The current proposal, deeply entwined in the same narrative, seeks to continue this agenda of articulation for a primarily North American audience. Instead of description and comparison, a 
starkly different analytical framework is deployed in the hope that this may allow reclamation of contested terminological territory and provide traction for the necessary articulation work.

\subsection{Benjamin's notion of 'aura'}

We begin with an establishing shot - an introductory device common to photography and film that sets the stage, or acquaints the viewer with the setting in which an action will take place. Here, instead of a sweeping panoramic view or an assessment of heritage and customs, this paper engages intimately with the narrative as Walter Benjamin describes below:

With the close-up, space expands; with slow motion movement is extended. The enlargement of a snapshot does not simply render more precise what in any case was visible, though unclear: it reveals entirely new structural formations of the subject (Benjamin, 1968 p. 236).
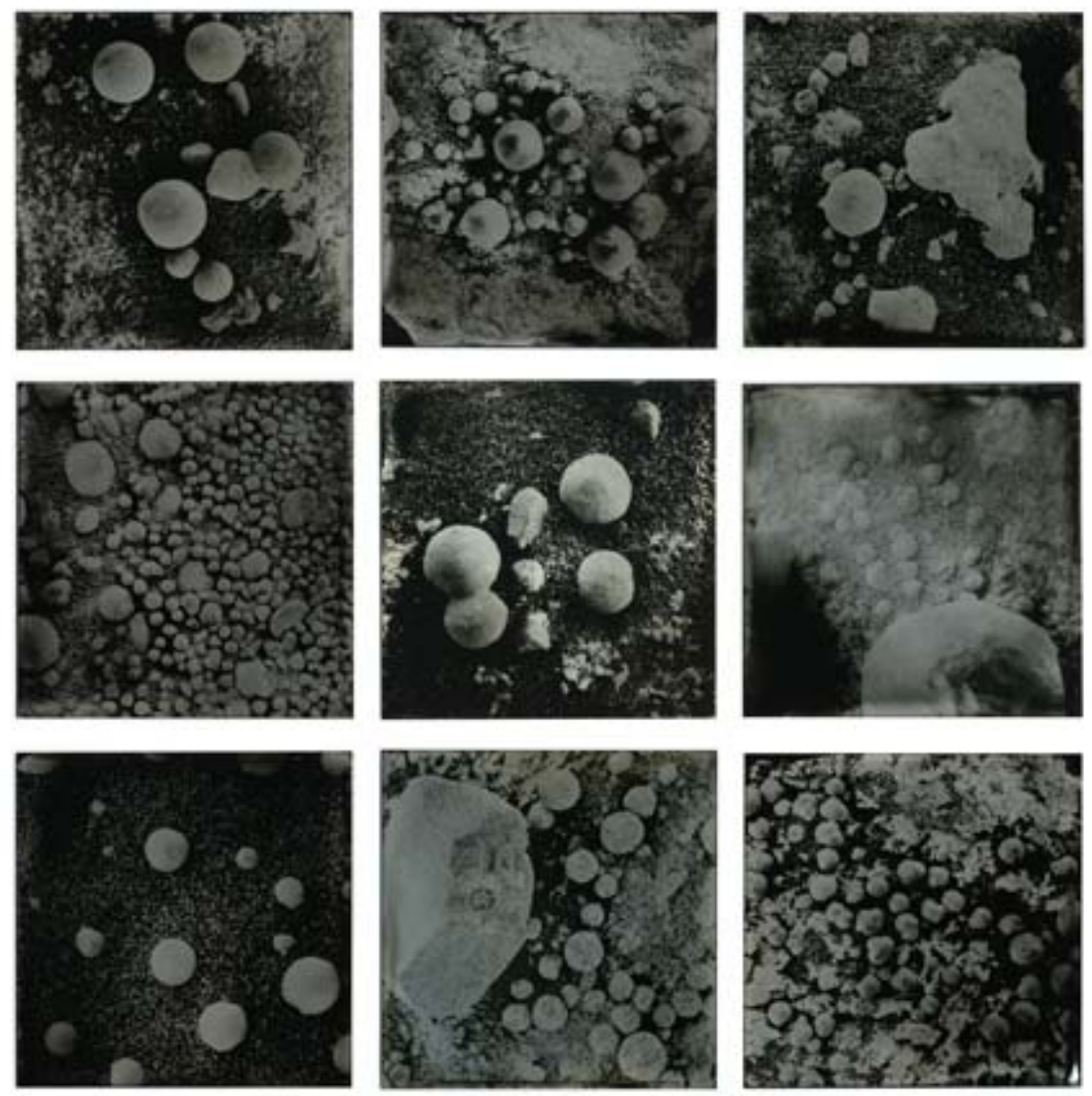

Figure 1: "nine microscopic views of orb like stones on mars" Collodion on tin. (Hocutt, 2011).

The starting point for this deliberation is Walter Benjamin's notion of aura.

...that which withers in the age of mechanical reproduction is the aura of the work of art. This is a symptomatic process whose significance points beyond the realm of art. One 
might generalize by saying: the technique of reproduction detaches the reproduced object from the domain of tradition. By making many reproductions it substitutes a plurality of copies for a unique existence. (Benjamin, 1968, p. 221).

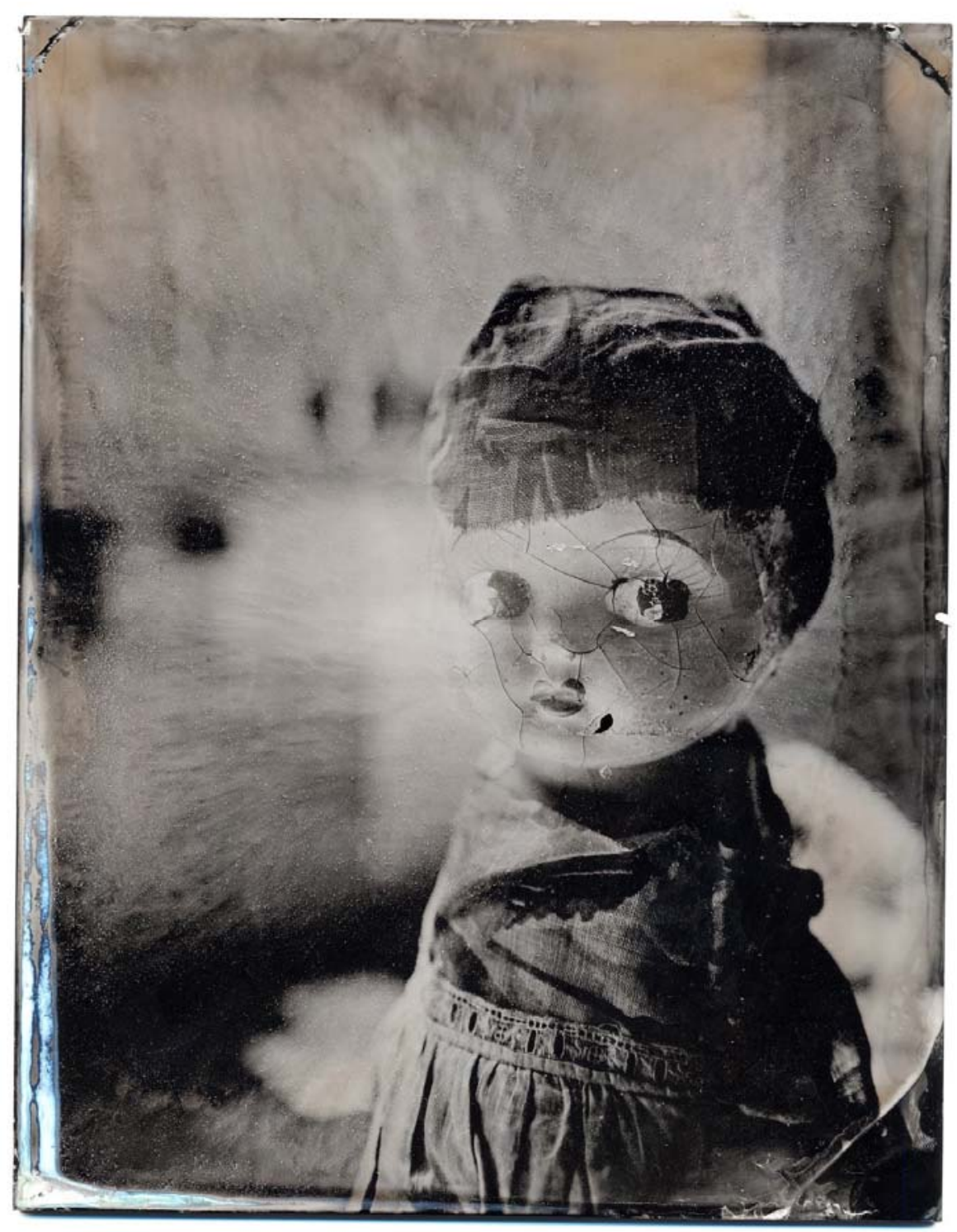

Figure 2: “doll” (Hocutt, 2009). Collodion on glass plate.

The notion of aura is an aesthetic of the past, grounded in ritual (the reason for the creation), and tradition that has been nearly eliminated by the disassociation and fragmentation of modernity. The aura of a work of art exists in a specific temporal and spatial realm that reproductions are not able to mimic. It invokes values of tradition, uniqueness and authenticity that are ultimately shattered by the technology of mechanical reproduction (Benjamin, p. 221). 